\title{
Aerosol specification in single-column Community Atmosphere Model version 5
}

\author{
B. Lebassi-Habtezion and P. M. Caldwell \\ Lawrence Livermore National Laboratory, P.O. Box 808, Livermore, CA 94551, USA \\ Correspondence to: P. M. Caldwell (caldwell19@1lnl.gov)
}

Received: 14 October 2014 - Published in Geosci. Model Dev. Discuss.: 17 November 2014

Revised: 13 February 2015 - Accepted: 3 March 2015 - Published: 27 March 2015

\begin{abstract}
Single-column model (SCM) capability is an important tool for general circulation model development. In this study, the SCM mode of version 5 of the Community Atmosphere Model (CAM5) is shown to handle aerosol initialization and advection improperly, resulting in aerosol, clouddroplet, and ice crystal concentrations which are typically much lower than observed or simulated by CAM5 in global mode. This deficiency has a major impact on stratiform cloud simulations but has little impact on convective case studies because aerosol is currently not used by CAM5 convective schemes and convective cases are typically longer in duration (so initialization is less important). By imposing fixed aerosol or cloud-droplet and crystal number concentrations, the aerosol issues described above can be avoided. Sensitivity studies using these idealizations suggest that the Meyers et al. (1992) ice nucleation scheme prevents mixed-phase cloud from existing by producing too many ice crystals. Microphysics is shown to strongly deplete cloud water in stratiform cases, indicating problems with sequential splitting in CAM5 and the need for careful interpretation of output from sequentially split climate models. Droplet concentration in the general circulation model (GCM) version of CAM5 is also shown to be far too low $\left(\sim 25 \mathrm{~cm}^{-3}\right)$ at the southern Great Plains (SGP) Atmospheric Radiation Measurement (ARM) site.
\end{abstract}

\section{Introduction}

The single-column model (SCM) version of the Community Atmosphere Model (CAM) is a very important tool for development of model parameterizations. One advantage of the SCM is that it is much more computationally afford- able, which allows developers to easily test a wide variety of model changes. Another advantage is that there exists a large number of standard SCM cases which can be used to evaluate model behavior over a wide variety of climate regimes. These case studies (typically organized by the Global Energy and Water Experiment Cloud System Study (GCSS) Boundary Layer Cloud Working Group and later by the Global Atmosphere System Studies (GASS) Panel) are typically based on observations from field campaigns which provide data for driving the SCM and for evaluating its output (Randall et al., 2003). Cases tend to focus on a single meteorological phenomenon, which makes them perfect test beds for thinking deeply about the processes responsible for model behavior.

In the first GCSS intercomparison (Moeng et al., 1996), liquid water path (LWP) in nocturnal stratocumulus were found to vary by a factor of 5 between different large-eddy simulation (LES) models. The source of this spread could not be identified because the LES models differed widely in all aspects of their design. This experience started a long tradition of idealizing aspects of models participating in SCM intercomparisons in order to isolate the source of differences between simulations. In particular, variables normally predicted by general circulation models (GCMs) are often hardcoded to observed values in SCM studies in order to separate errors in their prediction from errors in other parts of the model. By idealizing or specifying aspects of a simulation, the processes responsible for model bias can be illuminated, thus providing a pathway towards model improvement.

A significant fraction of the uncertainties in climate projections results from the representation of aerosol (Haywood and Boucher, 2000; Forster et al., 2007). Aerosols affect climate by directly absorbing and reflecting atmospheric radiation (known as the direct effect) and by changing cloud op- 
tical properties and lifetimes (known as aerosol indirect effects). In recognition of their importance, developing aerosol parameterizations has become a high priority in the climate modeling community.

The inclusion of prognostic aerosol in version 5 of CAM (CAM5) has been a major milestone in its development (Liu et al., 2012; Ghan et al., 2012). However, horizontal advective tendencies are required for prognostic aerosol and these cannot be calculated from a single column. This problem was not considered in the development of CAM5 aerosol treatment, and as a result horizontal advective tendencies for aerosol are hard-coded to zero in SCM mode (i.e., advection neither increases or decreases aerosol concentrations).

Another problem is that CAM5 SCM initializes all aerosol mass mixing ratios to zero. As a result, aerosol concentrations in SCM runs are unrealistically low compared to observations or GCM simulations until surface emissions (specified from observed climatology) loft sufficient aerosol. Since this process can take several days (Schubert et al., 1979), SCM case studies (particularly stratiform cloud studies, which tend to be short) are plagued by extremely low aerosol. The goal of this study is to test the impact of CAM5 SCM aerosol treatment for a variety of classic case studies and to evaluate the efficacy of several potential solutions to the problems induced by unrealistically low aerosol concentration.

\section{Methods}

\subsection{Model setup}

All simulations in this paper were performed using CAM5, which is described in detail in Neale et al. (2012). Briefly, turbulent transport at all model levels in CAM5 is computed following Bretherton and Park (2009). Stratiform cloud fraction and condensation/evaporation is computed following Park et al. (2014) and stratiform microphysics is handled according to Morrison and Gettelman (2008) and Gettelman et al. (2010). Shallow convection follows Park and Bretherton (2009), while deep convection is parameterized according to Zhang and McFarlane (1995) as modified by Richter and Rasch (2008). Radiation is calculated using the rapid radiative transfer model (RRTMG) radiation scheme (Mlawer et al., 1997). Aerosol are handled by the three mode simplified modal aerosol model (MAM3; Liu et al., 2012; Ghan et al., 2012) with accumulation, Aitken, and coarse modes. MAM3 is capable of treating complex aerosol physical, optical, and chemical processes and simulating aerosol size, mass, and number distributions. The aerosol size distribution is lognormal, and internal and external mixing between aerosol components is assumed in the model.

In SCM mode, a column from the global model is extracted and driven by prescribed winds and horizontal advective tendencies (Hack and Pedretti, 2000). This results in an idealized version of the GCM where code related to fluid flow is replaced by externally imposed data but the parameterized physics component of the model retains its full complexity. All SCM runs use a time step of 1200 s and 30 vertical grid levels (with $\sim 20$ levels in the free troposphere).

Most of the simulations described in this paper are SCM runs as described in Sect. 2.3, but for comparison we conduct two 10-year-long GCM runs using the finite-volume dynamical core at $1.9 \times 2.5^{0}$ resolution. One simulation was done using the default prognostic-aerosol method and the other uses the prescribed aerosol functionality included in version 1.2 of the Community Earth System Model (CESM). Both GCM runs were driven by a repeating annual cycle of year 2000 sea surface temperature (SST), greenhouse gases, and aerosols. They use an $1800 \mathrm{~s}$ time step and the same 30 vertical levels used for the SCM runs.

\subsection{Proposed solutions}

As noted in the introduction, a problem with CAM5 SCM is that aerosols are initialized to zero and horizontal advection of aerosol is not treated realistically. As a result, aerosol concentrations in SCM runs are much lower than observed or simulated in GCM runs. In this section we outline three possible solutions to the problem of low aerosol concentration in CAM5 SCM.

1. Our first approach (hereafter called FixHydro) is to fix cloud-droplet $\left(N_{\mathrm{d}}\right)$ and ice crystal $\left(N_{\mathrm{i}}\right)$ number concentrations at observed values. Because $N_{\mathrm{d}}$ and $N_{\mathrm{i}}$ are the means through which aerosol affects cloud in CAM5, fixing these concentrations is a simple way to avoid cloud problems due to low aerosol in CAM5 SCM. The FixHydro approach is attractive because (a) these number concentrations are available for most popular SCM case studies and (b) specifying $N_{\mathrm{d}}$ and $N_{\mathrm{i}}$ isolates biases in the microphysics from biases related to aerosol treatment. Ability to isolate the parameterization responsible for bad behavior is critical for avoiding a model held together by compensating errors. One downside to FixHydro is that it does not alleviate clear-sky impacts of low aerosol. This is not a critical problem since clear-sky effects tend to be small relative to the radiative impact of cloud changes. Another downside to FixHydro is that it is not useful for testing the aerosol schemes themselves. These issues motivate our other solutions.

2. Our second method (hereafter called PrescAero) uses the new prescribed aerosol capability included in CESM version 1.2. PrescAero prescribes mass mixing ratios of aerosol species based on climatologies (derived from a long prognostic-aerosol run) for each month of the year for each grid cell. In global mode, prescribed aerosol values for each day are drawn from a lognormal distribution based on climatological values. This random sampling is used to capture nonlinear effects which are 
important to mean climate at high latitudes (J.-H. Yoon, personal communication, 2014). We turn this random sampling off in SCM mode because it would make SCM runs irreproducible and occasionally provides very unusual values which unnecessarily complicate interpretation of SCM results. Using climatological mean values in the SCM rather than random sampling should be sufficient for reproducing climatological mean behavior at lower latitudes; ensembles of SCM runs with varying aerosol content are probably needed to reproduce model climatology in polar regions.

3. In our last method, we apply observed mixing ratios and size distributions to the aerosols in MAM3. This method (hereafter named ObsAero) makes use of PrescAero code but imposes observed rather than modeled mass mixing ratios of the different aerosol species for all the modes. To use this approach, observed values are needed for the number concentrations of the aerosol mode $N_{j}$, the geometric mean dry radius $a_{m j}$, and the geometric standard deviation $\sigma_{j}$ of the multimode lognormal aerosol size distribution given by the following equation (Abdul-Razzak and Ghan, 2000)

$$
\frac{\mathrm{d} n}{\mathrm{~d} a}=\sum_{j=1}^{3} \frac{N_{j}}{\sqrt{2 \pi} \sigma_{j}} \exp \left\{-\frac{\ln ^{2}\left(\frac{a}{a_{m j}}\right)}{2 \ln ^{2} \sigma_{j}}\right\},
$$

where the summation is over all three aerosol modes (accumulation, Aitken, and coarse).

Each of our three solutions has advantages and disadvantages. Many case studies lack the information necessary for the ObsAero method and some lack $N_{\mathrm{d}}$ and $N_{\mathrm{i}}$ information needed for the FixHydro approach. For these cases, PrescAero is the only viable option. PrescAero is also the best choice if one's goal is to emulate the behavior of the GCM as closely as possible (since it uses aerosol values from the full model). But aerosol from GCM simulations is often a poor proxy for observed values (both because values at the time of observation may differ greatly from climatology and because the model climatology may be biased); therefore, fixes based on observed data are more appropriate for experiments which will be validated against observations at a particular time and place.

The goal of the experiment also plays a critical role in determining which fix is best. For example, FixHydro is clearly inappropriate for studying aerosol effects but its simplicity makes it optimal for teasing out errors in the microphysics scheme. ObsAero and FixHydro methods are useful for testing aerosol activation but not two-way cloud-aerosol interactions. Comparing FixHydro and ObsAero results may be the best way to identify whether biases come from aerosol activation or other processes. In short, there is no best approach to obtaining realistic aerosol in CAM5 SCM. Our goal in this paper is to prove that all three methods yield acceptable solutions and are suitable for use when needed.

If one's goal is to study interaction between cloud and aerosol, none of our proposed methods are appropriate. It would be relatively straightforward to add another SCM option which initializes aerosol to observed or model-specified values and allows the model to ingest horizontal aerosol advective tendencies. We do not do this because we do not know of any SCM case studies where such information is available, our personal research plans do not require this functionality, and global simulations with specified meteorology (e.g., Rasch et al., 1997) already fill this role.

\subsection{SCM cases}

In order to test aerosol effects over a range of climatologically important cloud regimes we analyze results from four case studies, each highlighting a different type of cloud. These cases include drizzling subtropical stratocumulus, mixed-phase Arctic stratocumulus, maritime shallow convection, and continental deep convection. The details of these experiments conducted are summarized below.

\subsubsection{DYCOMS RF02 Case}

Subtropical stratocumulus are important because of all cloud types they have the biggest impact on the planetary radiation budget (Hartmann et al., 1992), and difficulty in simulating them is a leading source of uncertainty in climate sensitivity (e.g., Bony and Dufresne, 2005). Because they are important yet hard to simulate, stratocumulus have been the focus of a large number of field campaigns. Research flight 2 of the second Dynamics and Chemistry of Marine Stratocumulus field campaign (hereafter DYCOMS RF02) sampled drizzling stratocumulus off the coast of California during the night of 11 July 1999. Data from this flight formed the basis for an SCM intercomparison by Wyant et al. (2007; hereafter W07) and an LES intercomparison by Ackerman et al. (2009). Like previous intercomparisons, the SCMs studied varied greatly in their ability to predict stratocumulus properties. Precipitation was found to play an important role in these simulations by reducing LWP and (to a lesser extent) reducing cloud-top entrainment.

Our experimental configuration (outlined in Table 1) follows the specifications of W07 with a few exceptions. One difference is that radiation is calculated using RRTMG instead of the idealized scheme used in W07. We also kept $u$ and $v$ for our simulations constant instead of calculating winds from specified geostrophic wind profiles (which is reasonable since shear was not important in DYCOMS RF02). While these changes make our simulations slightly less comparable to the runs in W07, they are simpler to implement and produce runs which are still realistic enough to be reasonably compared against observations. We also turn off cloud processes above $700 \mathrm{hPa}$ to prevent ice formation at the 
Table 1. Initial and boundary conditions for DYCOMS RF02, MPACE-B, and RICO cases. All heights $z$ are in meters and all pressures $p$ are in $\mathrm{hPa}$. Boundary layer height and vertical velocity are, respectively, $z_{i}$ and $w$ in height coordinates and $p_{i}$ and $\omega$ in pressure coordinates. N/A indicates a quantity which is not used or is calculated by the model itself. $q_{\mathrm{t}}$ is total water mixing ratio, $\theta$ is potential temperature, and $\theta_{1}$ is liquid water potential temperature. One of the three aerosol modes for each case is omitted because it has zero mass.

\begin{tabular}{|c|c|c|c|}
\hline & DYCOMS RF02 & MPACE-B & RICO \\
\hline Run time (h): & 6 & 12 & 24 \\
\hline $\operatorname{SHF}\left(\mathrm{W} \mathrm{m}^{-2}\right)$ : & 16 & 136.5 & N/A \\
\hline $\operatorname{LHF}\left(\mathrm{W} \mathrm{m}^{-2}\right)$ : & 93 & 107.7 & N/A \\
\hline$u\left(\mathrm{~m} \mathrm{~s}^{-1}\right):$ & $3+4.3 z / 1000$ & -13 & $-1.9-8 \min \left(z, z_{i}\right) / z_{i}$ \\
\hline$v\left(\mathrm{~m} \mathrm{~s}^{-1}\right)$ & $-9+5.6 z / 1000$ & -3 & -3.8 \\
\hline $\begin{array}{l}\text { vertical } \\
\text { velocity: }\end{array}$ & $w=-3.75 \times 10^{-6} z\left(\mathrm{~m} \mathrm{~s}^{-1}\right)$ & $\omega=80 \min \left(p, p_{i}\right) / p_{i}\left(\mathrm{mb} \mathrm{day}^{-1}\right)$ & $w=-0.5 \min (z, 2260) / 2260\left(\mathrm{~m} \mathrm{~s}^{-1}\right)$ \\
\hline $\begin{array}{l}\text { Large-scale } \\
q_{t} \text { tend } \\
\left(\mathrm{g} \mathrm{kg}^{-1} \mathrm{day}^{-1}\right)\end{array}$ & 0 & $\min \left\{-0.164,-3\left[1-\left(p_{s}-p\right) / 151.71\right]\right\}$ & $-1+1.3456 \min \{z, 2980\} / 2980$ \\
\hline $\begin{array}{l}\text { Large-scale } \\
T \text { tend } \\
\left(\mathrm{Kday}^{-1}\right) \text { : }\end{array}$ & 0 & $\min \left\{-4,-15\left[1-\left(p_{s}-p\right) / 218.18\right]\right\}$ & -2.5 \\
\hline $\begin{array}{l}\text { initial } q_{t} \\
\left(\mathrm{~g} \mathrm{~kg}^{-1}\right)\end{array}$ & $\begin{array}{l}9.45 \mathrm{~g} \mathrm{~kg}^{-1} \text { if } z<z_{i}, \text { else } \\
5-3\left(1-e^{\left(z_{i}-z\right) / 500}\right)^{1 / 3}\end{array}$ & $\begin{array}{l}1.95 \text { if } p>p_{i}, \text { else } \\
0.291+0.00204(p-590)\end{array}$ & $\begin{array}{l}16-2.2 z / 740 \text { if } z<740 \\
13.8-11.4(z-740) / 2520 \text { if } 740<z<3260 \\
2.4-0.6(z-3260) / 740 \text { else }\end{array}$ \\
\hline initial $\theta_{l}(\mathrm{~K})$ : & $\begin{array}{l}288.3 \mathrm{~K} \text { if } z<z_{i}, \text { else } \\
295+\left(z-z_{i}\right)^{1 / 3}\end{array}$ & $\begin{array}{l}269.2 \text { if } p>p_{i}, \text { else } \\
275.33+0.0791(815-p)\end{array}$ & $\begin{array}{l}297.9 \text { if } z<740, \text { else } \\
297.9+19.1(z-740) /(4000-740)\end{array}$ \\
\hline $\begin{array}{l}\text { For FixHydro: } \\
\qquad N_{\mathrm{d}}\left(\mathrm{cm}^{-3}\right) \\
N_{\mathrm{i}}\end{array}$ & $\begin{array}{l}55 \\
\text { N/A }\end{array}$ & $\begin{array}{l}50 \\
0.16 \mathrm{~L}^{-1}\end{array}$ & $\begin{array}{l}70 \\
\text { N/A }\end{array}$ \\
\hline $\begin{array}{l}\text { For ObsAero: } \\
\text { Mode: } \\
\text { composition } \\
\text { no. concentration } \\
\text { mode radius } \\
\text { geometric } \sigma \\
\text { Mode: } \\
\text { composition } \\
\text { no. concentration } \\
\text { mode radius } \\
\text { geometric } \sigma\end{array}$ & $\begin{array}{l}\text { Aitken } \\
100 \% \mathrm{SO}_{4} \\
125 \mathrm{~cm}^{-3} \\
0.011 \mu \mathrm{m} \\
1.2 \\
\text { accumulation } \\
100 \% \mathrm{SO}_{4} \\
65 \mathrm{~cm}^{-3} \\
0.06 \mu \mathrm{m} \\
1.7\end{array}$ & $\begin{array}{l}\text { accumulation } \\
70 \% \mathrm{SO}_{4}, 30 \% \text { particulate organic matter } \\
72.2 \mathrm{~cm}^{-3} \\
0.052 \mu \mathrm{m} \\
2.04 \\
\text { coarse } \\
10 \% \mathrm{SO}_{4}, 85 \% \text { sea salt, } 5 \% \text { dust } \\
1.8 \mathrm{~cm}^{-3} \\
1.3 \mu \mathrm{m} \\
2.5\end{array}$ & $\begin{array}{l}\text { Aitken } \\
100 \% \mathrm{SO}_{4} \\
90 \mathrm{~cm}^{-3} \\
0.03 \mu \mathrm{m} \\
1.28 \\
\text { accumulation } \\
100 \% \mathrm{SO}_{4} \\
150 \mathrm{~cm}^{-3} \\
0.14 \mu \mathrm{m} \\
1.75\end{array}$ \\
\hline
\end{tabular}

tropopause, which would otherwise occur due to interaction between the idealized SCM forcing specifications and subgrid variability assumptions in CAM5. Observed aerosol information (for testing the ObsAero method) were taken from Ackerman et al. (2009), who assumed aerosol was comprised entirely of sulfate and chose parameters for the bimodal lognormal distribution (Eq. 1) in order to have $N_{\mathrm{d}}$ match the observed droplet concentration value of $55 \mathrm{~cm}^{-3}$.

\subsubsection{MPACE-B Case}

Our second case comes from the Mixed-Phase Arctic Cloud Experiment (MPACE), which sampled clouds over open ocean near Barrow, AK. We focus particularly on the portion of this experiment between 9 October, 17:00 UTC to 10 October, 05:00 UTC, 2004 (known as MPACE-B), a period when mixed-phase stratocumulus were observed. This case was the subject of an intercomparison by Klein et al. (2009; hereafter K09). Most models participating in this intercomparison greatly underestimated the observed LWP because conversion to ice was too efficient. We chose this case because mixed-phase stratocumulus are very important to the polar surface budget, yet models (including CAM5) have a hard time simulating these clouds. MPACE-B is attractive because it includes both liquid and ice processes without being overly complicated. Our case setup (listed in Table 1) is similar to K09 with a few notable exceptions. We again specify winds at all levels while K09 advocates nudging winds 
below $700 \mathrm{hPa}$. We nudge thermodynamics variables to initial conditions above $700 \mathrm{hPa}$ with a timescale of $1 \mathrm{~h}$, while K09 specifications require all variables to be kept at their initial values above $700 \mathrm{hPa}$. These changes were again implemented for convenience and are not expected to have dramatic effects on our simulations.

\subsubsection{RICO case}

Shallow convection is another important cloud type with major impact on climate sensitivity (e.g., Medeiros et al., 2008). To sample this cloud type, we use data from the Rain in $\mathrm{Cu}$ mulus over Ocean (RICO) experiment, which was conducted on the upwind side of the islands of Antigua and Barbuda during the winter of 2004 (Rauber et al., 2007). Unlike previous experiments such as the Atlantic Trade Wind Experiment (ATEX) and Barbados Oceanographic and Meteorological Experiment (BOMEX) which did little to measure clouds and precipitation, RICO has extensive cloud-related measurements, which make it useful for studying shallow cumulus clouds and their precipitation. Unfortunately, cloud data came at the expense of large-scale information, forcing modeling studies to use idealized composite information which is not directly comparable to time-evolving observations. A study by vanZanten et al. (2011; hereafter VZ11) describes the results of an LES intercomparison based on this composite data. An SCM intercomparison was planned (http:// www.knmi.nl/samenw/rico/index.html) but never published. Our simulations are a blend between LES and SCM specifications as listed in Table 1 and described below. One unique aspect of the RICO case is that radiation tendencies are included in the prescribed large-scale temperature tendency. As a result, we had to turn off the shortwave and longwave radiation schemes. The case was designed specifically to be energetically and moisture balanced, and as a result we found we did not need to use nudging to obtain stable simulations.

\subsubsection{ARM95}

The last case we consider is an 18-day-long simulation of summertime continental convection spanning 18 July to 3 August 1995 at the Atmospheric Radiation Measurement (ARM) program's southern Great Plains (SGP) site. We included this case because for a long time it was the only SCM case that was included in the released version of CAM. This case is useful because it tests the model's deep convective scheme (which plays a huge role in determining model climate), yet is extratropical so the imposed vertical velocity assumption of typical SCMs is less problematic (e.g., Sobel and Bretherton, 2000). This case was the subject of an intercomparison of 11 SCMs and one coarse LES by Ghan et al. (2000). In this study, temporal variability in the models exceeded observed values, which was interpreted as forcing error since all models behaved similarly. Large temperature and moisture biases were reported over the simulation unless nudging was used; we do not use nudging despite this warning because clouds form at all levels during the simulation and nudging areas with clouds makes it hard to tell whether model physics or nudging is causing the modeled behavior. Advective forcing was generated by the State University of New York (SUNY) objective analysis method (Zhang et al., 2001) and surface fluxes were specified with the Doran et al. (1998) surface analysis technique using the Simple Biosphere (SiB2) model (Ghan et al., 2000). Forcings for this case are not included in Table 1 because they vary in time, which makes them impossible to represent compactly in a table. Aerosol and cloud number densities are not available for this case, so only default and PrescAero methods were tested.

\section{Results and discussion}

\subsection{DYCOMS RF02}

Table 2 shows observed and modeled cloud-related variables averaged during the last $2 \mathrm{~h}$ of the $6 \mathrm{~h}$ DYCOMS RF02 simulations. In addition to $N_{\mathrm{d}}$ and surface precipitation $(\operatorname{Pr})$, we include LWP both before and after microphysics was called $\left(L W P_{\text {pre }}\right.$ and $L W P_{\text {post }}$, respectively). These values are different because CAM5 sequentially updates the model state after each parameterization is applied. As described in Gettelman et al. (2015), $\mathrm{LWP}_{\text {pre }}$ is often much bigger than $\mathrm{LWP}_{\text {post }}$ because microphysics tends to deplete cloud water and when it acts in isolation over the long model time step a great deal of water can be lost. We also include cloud base, $z_{\mathrm{b}}$ (computed by identifying the first layer from the bottom with cloud fraction exceeding 0.5 , then linearly interpolating between this layer and the one below it to get the exact height where cloud fraction $=0.5$ ) and cloud-top height, $z_{i}$ (computed by identifying the top-most layer with total water mixing ratio $q_{\mathrm{t}}>8 \mathrm{~g} \mathrm{~kg}^{-1}$ and linearly interpolating between this layer and the one above it to find the exact height where $q_{\mathrm{t}}=8 \mathrm{~g} \mathrm{~kg}^{-1}$ ). Cloud-top entrainment velocity $w_{\mathrm{e}}=\delta z_{i} / \delta t-w_{\mathrm{s}}$ was also computed.

The default method underestimated the observed $N_{\mathrm{d}}$ (i.e., $55 \mathrm{~cm}^{-3}$ ), while ObsAero and particularly PrescAero overestimated $N_{\mathrm{d}}$. As expected, runs with higher $N_{\mathrm{d}}$ tend to precipitate less and as a result have higher LWP. LWP computed before microphysics is too high except for the default case. Values after microphysics show more variability, with the default case being too low and the FixHydro and PrescAero being too high. The difference between preand post-microphysics values illustrates the difficulty of interpreting output from sequentially split climate models.

Cloud base and cloud top were both slightly higher than observed yet entrainment was much smaller than observed. This suggests that the prescribed subsidence may be too weak in this case study. Surface precipitation is too weak when realistic $N_{\mathrm{d}}$ is used. This could be due to excessive 
Table 2. Data averaged over the last $2 \mathrm{~h}$ of the DYCOMS RF02 simulations. Observations are from W07. $N_{\mathrm{d}}$ is the average over the in-cloud portion of all cloudy levels of the column.

\begin{tabular}{lrrrrrrr}
\hline & $\begin{array}{r}N_{\mathrm{d}} \\
\left(\mathrm{cm}^{-3}\right)\end{array}$ & $\begin{array}{r}\mathrm{LWP}_{\text {pre }} \\
\left(\mathrm{g} \mathrm{m}^{-2}\right)\end{array}$ & $\begin{array}{r}\mathrm{LWP}_{\text {post }} \\
\left(\mathrm{g} \mathrm{m}^{-2}\right)\end{array}$ & $\begin{array}{r}w_{\mathrm{e}} \\
\left(\mathrm{mm} \mathrm{s}^{-1}\right)\end{array}$ & $\begin{array}{r}z_{\mathrm{b}} \\
(\mathrm{m})\end{array}$ & $\begin{array}{r}z_{i} \\
(\mathrm{~m})\end{array}$ & $\begin{array}{r}\text { Surf Pr } \\
\left(\mathrm{mm} \mathrm{day}^{-1}\right)\end{array}$ \\
\hline Obs & 55 & $80-120$ & $80-120$ & $6-7.6$ & $\sim 450$ & $\sim 800$ & 0.35 \\
Default & 33 & 103 & 73 & 4.2 & 475 & 803 & 0.31 \\
PrescAero & 139 & 137 & 126 & 4.0 & 473 & 816 & 0.04 \\
ObsAero & 74 & 146 & 119 & 3.4 & 492 & 815 & $8.5 \times 10^{-6}$ \\
FixHydro & 55 & 174 & 145 & 3.6 & 465 & 818 & $6.9 \times 10^{-6}$ \\
\hline
\end{tabular}

re-evaporation of precipitation below the cloud base. This is consistent with the fact that the ObsAero and FixHydro models have the highest below-cloud base evaporation of precipitation $\left(5.85 \times 10^{-5} \mathrm{~g} \mathrm{~kg}^{-1} \mathrm{~s}^{-1}\right.$ and $4.45 \times 10^{-5} \mathrm{~g} \mathrm{~kg}^{-1} \mathrm{~s}^{-1}$, respectively), while the default and PrescAero have lower values $\left(3.62 \times 10^{-5} \mathrm{~g} \mathrm{~kg}^{-1} \mathrm{~s}^{-1}\right.$, and $1.33 \times 10^{-5} \mathrm{~g} \mathrm{~kg}^{-1} \mathrm{~s}^{-1}$, respectively).

Figure 1a shows $N_{\mathrm{d}}$ profiles of the different aerosol specification cases averaged over the last $2 \mathrm{~h}$ of the simulation period. We have also included the 10-year July-average $N_{\mathrm{d}}$ profile of the corresponding 3-D CAM5 run in which $N_{\mathrm{d}}$ values were extracted at the closest grid point to the DYCOMS RF02 location. The specified-aerosol SCM cases show higher $N_{\mathrm{d}}$ values at the cloud base and slightly lower values at the cloud top. This is inconsistent with observations, which tend to show constant values throughout the cloud (e.g., Martin et al., 1994). The default run showed the lowest $N_{\mathrm{d}}$ values and PrescAero showed the highest. Low $N_{\mathrm{d}}$ for the default scheme is expected because it initializes aerosol to zero (as noted above); aerosol in the default simulation increased over time due to surface emission (not shown). The 3-D model $N_{\mathrm{d}}$ values are as high as the PrescAero case but the whole profile is shifted towards the surface. Collapsed boundary layers like this occur when stratocumulus become too thin to maintain the turbulence necessary to support a deep boundary layer. Differences in behavior between the SCM and GCM runs are unsurprising because the former were initialized to a well-mixed profile and driven by observed large-scale conditions for a short time period, while the latter had 10 years to develop biases and were driven by large-scale conditions from the model itself. Additionally, SCM runs are nocturnal while GCM runs include both day and night. This is relevant since solar radiation damps turbulence, reducing boundary-layer height (e.g., Caldwell et al., 2005). The fact that the GCM results look very different from the SCM results indicates that the source of GCM bias either takes a long time to spin up or is related to large-scale conditions in the GCM which differ from those sampled during DYCOMS RF02. This is useful information because it tells us that GCM biases in this case cannot be understood solely by analyzing SCM runs.

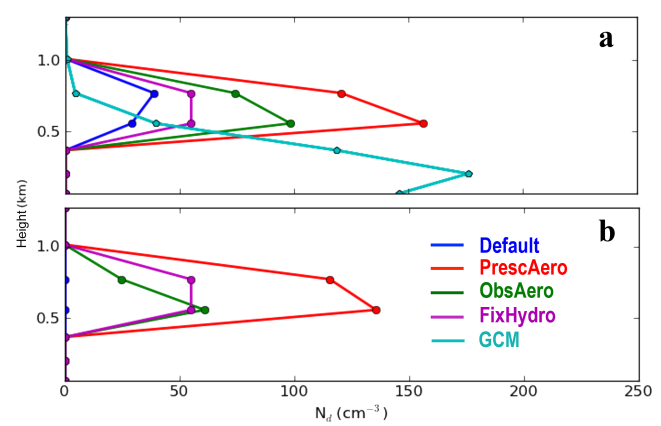

Figure 1. Profiles of in-cloud droplet number concentrations $\left(N_{\mathrm{d}}\right)$ for DYCOMS RF02. GCM values are July climatologies extracted from a 10-year-long prognostic-aerosol GCM run at the location of DYCOMS RF02. (a) is for runs where condensate is detrained (the default model behavior) and (b) shows runs where all detrained water is in vapor phase.

Even though stratocumulus are typically thought to be nonconvective, shallow convection is triggered occasionally in our DYCOMS RF02 simulations. This detrainment is a major source of $N_{\mathrm{d}}$ in simulations with low aerosol. Convective detrainment can create droplets out of thin air because CAM5 convection schemes detrain cloud droplets at a fixed droplet mean volume radius with no dependence on aerosol at all. Convection triggers more often in the default run, perhaps because strong precipitation due to low $N_{\mathrm{d}}$ tends to cause more decoupled, convective conditions. In order to isolate the effect of convective detrainment on $N_{\mathrm{d}}$, we conducted a set of sensitivity experiments where convection detrains vapor rather than condensate. $N_{\mathrm{d}}$ profiles from these experiments are shown in Fig. 1b. This figure reveals that almost all of the droplets in the default case are created by convective detrainment. Detrainment also plays a secondary but non-negligible role in the PrescAero and ObsAero cases, especially near the cloud top.

Figure 2 shows the temporal evolution of $\mathrm{LWP}_{\text {pre }}$ and $\mathrm{LWP}_{\text {post }}$ from the DYCOMS RF02 case. There is large variability in LWP during the first few hours in all cases, with variability lasting longest and having largest amplitude in the default run. ObsAero shows good agreement with obser- 

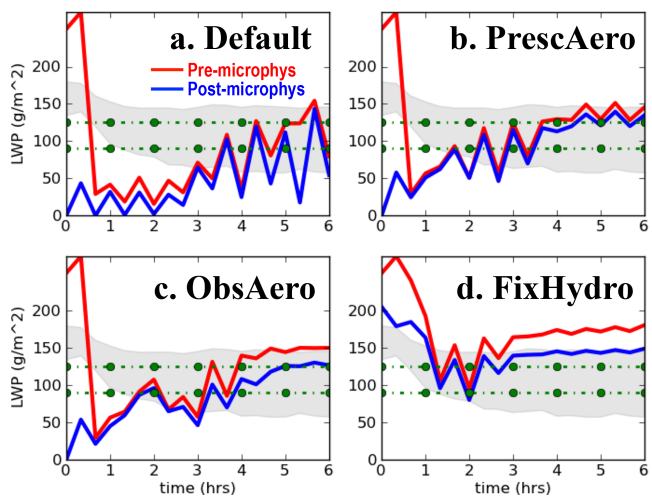

Figure 2. Time series of LWP before and after microphysics for DYCOMS RF02. The shaded area indicates the range of LES values averaged over the last $4 \mathrm{~h}$ of the simulation period from Stevens and Seifert (2008) and the area bounded by dots indicates the range of observational uncertainty from Stevens et al. (2003).

vations, while PrescAero and FixHydro LWP was too high (consistent with its overpredicted $N_{\mathrm{d}}$ values).

In summary, the DYCOMS RF02 case shows strong sensitivity to aerosol specification. In the default case, detrainment from shallow convection is a major source of $N_{\mathrm{d}}$, which artificially limits sensitivity to aerosol burden. Interpretation of model LWP is very sensitive to whether it is sampled before or after microphysics.

\subsection{MPACE-B}

Table 3 shows observed and modeled cloud-related variables averaged during the last $4 \mathrm{~h}$ of the MPACE-B case. All runs except FixHydro substantially overestimate the observed $N_{\mathrm{i}}$ value. Because the Bergeron process efficiently freezes liquid when $N_{\mathrm{i}}$ is plentiful, these runs have zero LWP. The FixHydro case, on the other hand, has reasonable $N_{\mathrm{i}}$ and LWP, which illustrates the importance of cloud number densities for obtaining realistic simulations. The cloud layer for FixHydro is of approximately the right thickness but is slightly too high in the atmosphere. Its surface precipitation is a bit too high and its ice water path (IWP) is slightly too low.

Figure 3 shows height-normalized MPACE-B profiles of liquid water content (LWC) and ice water content (IWC) including and excluding snow mass as a function of scaled height, before and after microphysics. This figure is useful for interpreting our earlier conclusion that $L W P=0$ for all runs except FixHydro. Figure 3 a shows that all runs have LWP $>0$ before microphysics; therefore, the problem is that each microphysics step removes all LWC in these runs. LWC before microphysics is, however, underpredicted and cloud top is too shallow for these runs. This is unsurprising since in mixed-phase stratocumulus, radiative cooling of liquid at cloud top is the main source of boundary-layer turbulence (which is needed to supply the cloud layer with liquid and to maintain cloud-top height in the face of subsidence) and

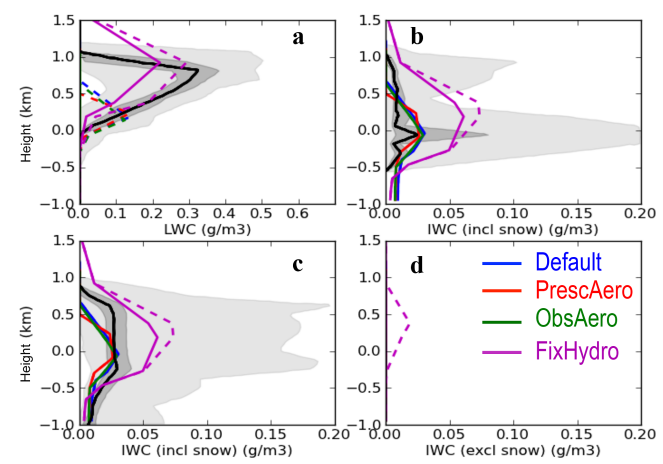

Figure 3. LWC and IWC profiles as a function of scaled height $\left(z / z_{\mathrm{b}}-1\right)$ for MPACE-B. Dashed lines indicate values before microphysics and solid lines indicate values after microphysics. (a) LWC profiles as function of scaled height. Dark shaded region ranges, light shaded region, and black solid line depict the median value, the inner $50 \%$ envelope, and the outer $50 \%$ envelope of the high frequency observed aircraft data, respectively (from K09). (b) The same as Fig. 3a but for IWC (including snow). (c) Same as Fig. 6b but using radar data from K09 as observations. (d) Same as Fig. 3b but excluding snow.

radiative transfer in CAM5 is computed after microphysics (at which point LWP is zero in these runs). In contrast with LWC, all runs showed reasonable agreement with observations for IWC except FixHydro, which is a bit higher than the bulk of the observational data (Fig. 3b and c). IWC consists, however, almost entirely of snow for all cases (Fig. 3d). Underprediction of liquid and dominance of ice over cloud ice have been reported previously for CAM5 (e.g., Gettelman et al., 2010; Liu et al., 2011).

Figure 4 shows the $N_{\mathrm{i}}$ profiles for all runs averaged over the last $4 \mathrm{~h}$ of the MPACE-B period along with the climatological October-average $N_{\text {i }}$ profile from our GCM run using data from the grid point closest to the MPACE-B location. All SCM runs except FixHydro have very similar $N_{\mathrm{i}}$ profiles. This is because ice nucleation at the temperatures sampled during MPACE-B occurs primarily through deposition/condensation freezing which is treated in CAM5 by a scheme (Meyers et al., 1992) which depends only on temperature and saturation vapor pressure. Compared to the observed value used by FixHydro, all other SCM runs and the GCM overpredict $N_{\mathrm{i}}$. This is a well-known model deficiency which is improved by newer nucleation parameterizations (e.g., Liu et al., 2011; Xie et al., 2013; English et al., 2014). $N_{\mathrm{d}}$ is not shown because its cloud-layer average is zero for all cases except FixHydro (where it is set to the observed value of $50 \mathrm{~cm}^{-3}$; see Table 3 ).

Profiles of cloud fraction are shown in Fig. 5. Interestingly, simulated cloud fraction compares well with aircraft and remote-sensing observations for all SCM cases even when LWP is zero and IWP (excluding snow) is negligibly small. Clouds with volume but no mass (commonly called empty clouds) were a problem with CAM3 and CAM4 (e.g., Han- 
Table 3. As in Table 2, but for MPACE-B using the last 4 simulated hours. Observations are from K09.

\begin{tabular}{llllllll}
\hline & $\begin{array}{l}N_{\mathrm{i}}\left(\mathrm{L}^{-1}\right), \\
N_{\mathrm{d}}\left(\mathrm{cm}^{-3}\right)\end{array}$ & $\begin{array}{l}\mathrm{LWP} \\
\left(\mathrm{g} \mathrm{m}^{-2}\right)\end{array}$ & $\begin{array}{l}\mathrm{IWP} \\
\left(\mathrm{g} \mathrm{m}^{-2}\right)\end{array}$ & $\begin{array}{l}w_{\mathrm{e}} \\
\left(\mathrm{mm} \mathrm{s}^{-1}\right)\end{array}$ & $\begin{array}{l}z_{\mathrm{b}} \\
(\mathrm{m})\end{array}$ & $\begin{array}{l}z_{i} \\
(\mathrm{~m})\end{array}$ & $\begin{array}{l}\text { Surf Pr } \\
\left(\mathrm{mm} \mathrm{day}^{-1}\right)\end{array}$ \\
\hline Obs & $0.16,50$ & $110-210$ & $8-30$ & - & $\sim 600$ & $\sim 1500$ & 0.25 \\
Default & $0.4,0$ & $3.96 \times 10^{-9}$ & 0.022 & 11.46 & 918 & 1476 & 0.82 \\
PrescAero & $0.7,0$ & $3.69 \times 10^{-9}$ & 0.018 & 15.37 & 984 & 1537 & 0.69 \\
ObsAero & $0.6,0$ & $3.64 \times 10^{-9}$ & 0.014 & 15.37 & 985 & 1537 & 0.68 \\
FixHydro & $0.16,50$ & 133 & 0.63 & 12.37 & 872 & 1783 & 0.50 \\
\hline
\end{tabular}

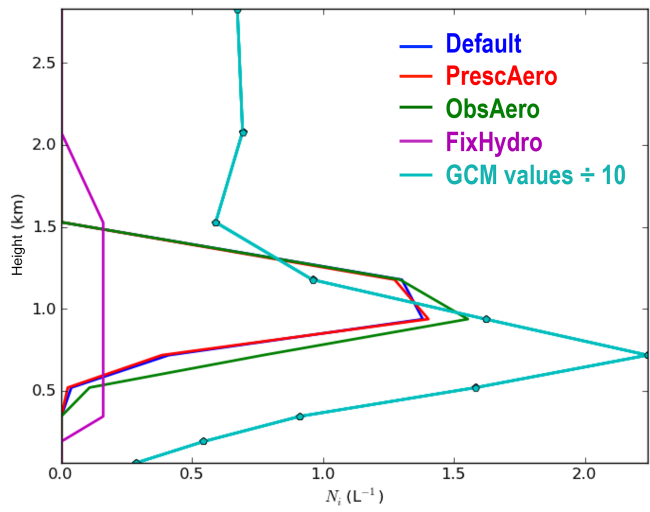

Figure 4. Profiles of in-cloud $N_{\mathrm{i}}$ values for MPACE-B. GCM values are 10-year July averages extracted at the location of MPACE-B divided by 10 in order to fit in the plot.

nay et al., 2009; Medeiros et al., 2012) because cloud fraction and condensation/evaporation schemes were disconnected. This disconnect was patched in CAM5 (Park et al., 2014), so finding empty clouds in this study was somewhat surprising. The empty clouds seen here for default, PrescAero, and ObsAero come from cloud fraction being computed before microphysics and left unchanged even after microphysics removes all condensate. Closer coupling between cloud fraction, condensation/evaporation, and microphysics is needed to solve this problem.

\subsection{RICO}

Table 4 shows $N_{\mathrm{d}}$, surface sensible heat flux (SHF), surface latent heat flux (LHF), cloud base mass flux (CBMF), cloud cover (the fraction of the sky which appears to a surface observer to be obscured by clouds), and LWP averaged over the last $4 \mathrm{~h}$ of the $24 \mathrm{~h}$ simulation of the RICO case for the four SCM simulations. We include LES intercomparison data from VZ11 as a crude proxy for truth here because (as discussed in Sect. 2.3), the RICO case study is created by compositing 2 months of observations and thus is not comparable with observations from any particular time. SCM behavior is almost identical for all runs even though aerosol and $N_{\mathrm{d}}$ vary substantially. This is because clouds in RICO are generated by the shallow convection scheme and (as mentioned

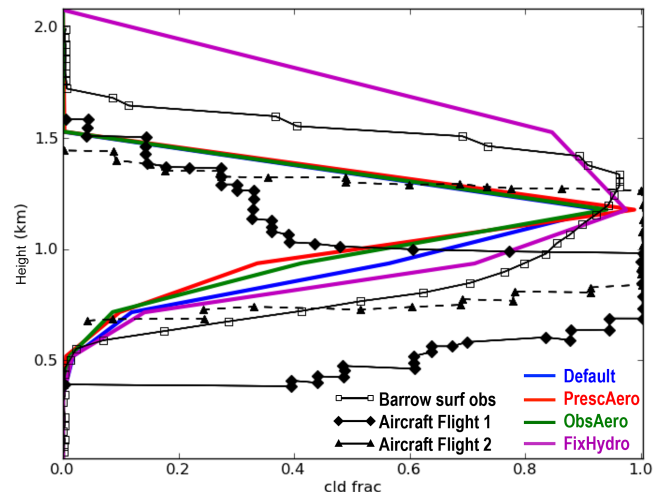

Figure 5. Time-averaged profiles of cloud fraction from models and observations as a function of height during the MPACE-B period. All observations are taken from K09.
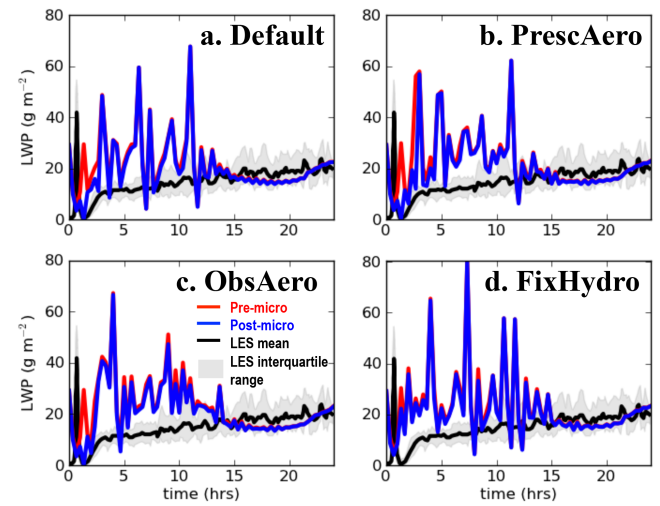

Figure 6. Time series of LWP during the RICO intensive observation period (IOP) period. LES data come from VZ11.

in Sect. 3.1) CAM5 convection schemes have no dependence on aerosol.

All SCM configurations overestimate the SHF, LHF, and CBMF relative to LES values but nonetheless capture cloud cover and LWP very well. Similar to DYCOMS RF02 results, LWP shows high temporal variability at the beginning of RICO SCM simulations which settles out over time (Fig. 6). Consistent with overpredicted CBMF, cloud-base condensate is overpredicted (Fig. 7a). As expected from previous studies (e.g., Siebesma et al., 2003), both condensate and 
Table 4. Data averaged over the last four $4 \mathrm{~h}$ of RICO runs. LES data are from VZ11.

\begin{tabular}{lrrrrrr}
\hline & $\begin{array}{r}N_{\mathrm{d}} \\
\left(\mathrm{cm}^{-3}\right)\end{array}$ & $\begin{array}{r}\mathrm{SHF} \\
\left(\mathrm{W} \mathrm{m}^{-2}\right)\end{array}$ & $\begin{array}{r}\mathrm{LHF} \\
\left(\mathrm{W} \mathrm{m}^{-2}\right)\end{array}$ & $\begin{array}{r}\mathrm{CBMF} \\
\left(\mathrm{m} \mathrm{s}^{-1}\right)\end{array}$ & $\begin{array}{r}\text { Cloud } \\
\text { Cover }\end{array}$ & $\begin{array}{r}\text { LWP } \\
\left(\mathrm{g} \mathrm{m}^{-2}\right)\end{array}$ \\
\hline LES & 70 & 8.5 & 158 & 0.026 & 0.19 & 19 \\
Default & 30 & 12.29 & 207.81 & 0.06 & 0.18 & 19.0 \\
PrescAero & 32 & 12.41 & 207.94 & 0.06 & 0.18 & 19.2 \\
ObsAero & 14 & 12.42 & 207.83 & 0.06 & 0.18 & 19.8 \\
FixHydro & 70 & 12.37 & 207.83 & 0.06 & 0.18 & 19.6 \\
\hline
\end{tabular}

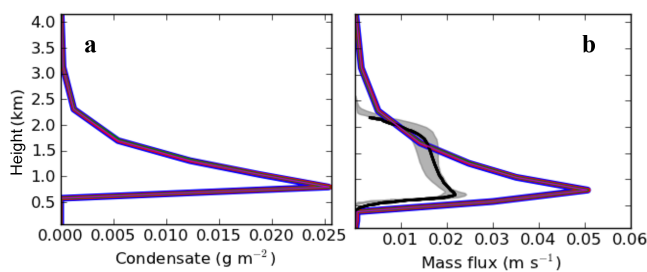

Figure 7. Time-averaged profiles of (a) condensate amount and (b) mass flux for RICO simulations. The colored line shows the SCM results (all simulations lie on top of one another). Shading in figure $8 \mathrm{~b}$ indicates ensemble inter quartile range and the solid black line is the ensemble mean. LES data are from VZ11.
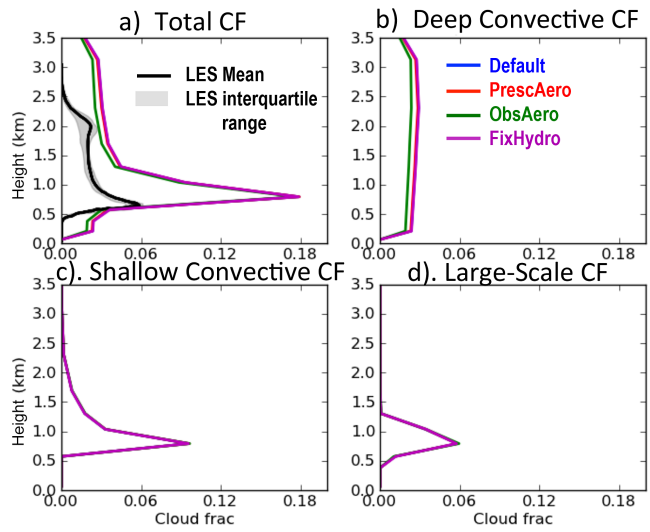

Figure 8. Time-averaged profiles cloud fraction (CF) quantities from RICO simulations. Default, PrescAero, and ObsAero all lie on top of one another. LES data are from VZ11.

mass flux decrease with distance above $z_{\mathrm{b}}$ (Fig. 7). Figure 8 breaks cloud cover into its vertical distribution (total cloud fraction) as well as cloud fraction contributions from shallow, deep, and large-scale contributions. Even though cloud cover is well predicted, cloud fraction is overpredicted by the SCMs because the maximum-random cloud overlap assumption used by CAM5 is inconsistent with cloud tilt and life-cycle effects found in real shallow convective conditions (Park and Bretherton, 2009). At cloud base, overestimation is due to both shallow convective and stratiform clouds. Modeled cloud extends further into the troposphere than observed due to triggering of deep convection.
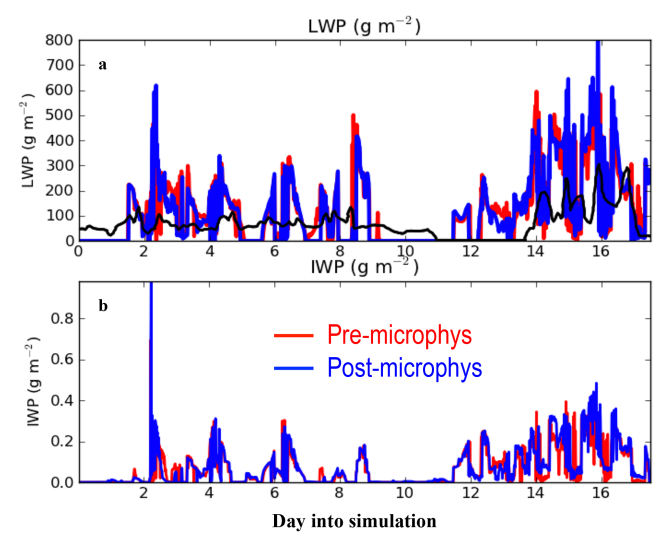

Figure 9. Time series of (a) LWP and (b) IWC during the ARM95 IOP period. The solid black line in (a) gives observations from $\mathrm{Xu}$ and Randall (2000).

\subsection{ARM95}

As noted above, ARM95 is much longer in duration than our other case studies. During the first 10 simulated days, a large-scale stationary upper-level trough sat over the continental USA, resulting in temporally variable cloud cover and precipitation. There followed a 3-day period of high pressure and clear skies, and the final 7 days consisted of stormy weather with high cloud cover and intense precipitation. As noted above, only the default and the PrescAero cases are simulated due to lack of observed $N_{\mathrm{d}}, N_{\mathrm{i}}$, and aerosol data.

Figure 9 shows the time series of LWP and IWP for the default and PrescAero cases. Observed LWP from Xu and Randall (2000) are also included. SCM runs capture the observed temporal trends but generally overestimate LWP. Default and PrescAero behave very similarly, which is consistent with our finding from RICO that aerosol is not important for convective cases.

Figure 10 shows $N_{\mathrm{d}}$ profiles from our simulations. Surprisingly, $N_{\mathrm{d}}$ is fairly similar for both SCM simulations even though visible aerosol optical depth differs substantially between these runs ( 0.163 for PrescAero and 0.081 for the default case). Typical observed $N_{\mathrm{d}}$ values at SGP are around $200 \mathrm{~cm}^{-3}$ (Frisch et al., 2002; Iacobellis and Somerville, 2006); therefore, modeled values have a large low bias. Is 


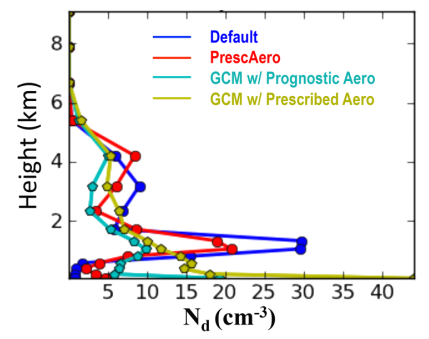

Figure 10. Profiles of in-cloud droplet number concentrations $\left(N_{\mathrm{d}}\right)$ during the ARM95 IOP period. GCM data are July averages over the 10 simulated years extracted at the location of ARM95.

this a problem with the SCM setup? We test this by including climatological July data for the GCM grid cell closest to SGP. We include GCM data from runs using both prognostic and prescribed aerosol. Both GCM runs show similarly low $N_{\mathrm{d}}$ values, indicating that this bias is related to aerosol values predicted by MAM3 rather than the specified values used for the prescribed aerosol mode. This bias has little impact on model behavior in the current version of CAM (because convection is independent of aerosol) but may cause problems in future model versions with more sophisticated convective microphysics.

\section{Summary and conclusions}

This study points out that aerosol treatment in CAM5 SCM is unrealistic and causes problems for non-convective case studies. The issue is that initial aerosol and horizontal aerosol advective tendencies are hard-coded to zero in SCM mode. Aerosol can still build up in the boundary layer from surface emissions, but the resulting aerosol loading is likely to be unrealistic because remote sources cannot be included. Additionally (and more importantly), SCMs are typically run for a shorter period than it takes to build up reasonable aerosol concentrations via surface emission and subsequent lofting into the cloud layer. As a result, aerosol in SCM runs is typically much lower than observed or simulated by the GCM. This limits the usefulness of the SCM for model development.

To fix this problem, we propose three idealizations: prescribing aerosol from CAM5 climatological values (PrescAero), prescribing aerosol from observations (ObsAero), and prescribing cloud-droplet and ice crystal numbers (FixHydro). We test these configurations against the default SCM (default) for four different cloud regimes: summertime mid-latitude continental convection (ARM95), shallow convection (RICO), subtropical drizzling stratocumulus (DYCOMS RF02), and mixed-phase stratocumulus (MPACE-B).

These fixes were found to have a big impact on nonconvective cases. However, aerosol and cloud number den- sity has almost no effect on convective cases because CAM5 convection does not depend on aerosol or droplet number. Cloud-droplet number at the site of the ARM95 case was found to be underpredicted in CAM5-GCM by a factor of 8 relative to observations. Even though this deficiency has no effect on CAM5 simulations, lack of dependence on aerosol or droplet number is unrealistic and will be fixed in future versions of CAM, which makes finding solutions to droplet number underprediction at SGP worth pursuing even if it does not affect the current model version.

Shallow convection is unexpectedly found to be triggered in DYCOMS RF02, where it artificially increases $N_{\mathrm{d}}$ because convectively detrained condensate is partitioned into droplets according to an assumed volume-mean radius rather than a dependency on available cloud condensation nuclei. Another finding is that the Meyers deposition/nucleationfreezing scheme in CAM5 is too active in the temperature and moisture conditions sampled during MPACE-B. As a result, ice crystal number concentration is too high in all of our SCM and GCM runs except FixHydro (which fixes $N_{\mathrm{i}}$ at observed values). When observed $N_{\mathrm{i}}$ is used, LWP matches observations. Otherwise microphysics depletes all liquid water whenever it is called. This results in empty clouds which have volume but no mass. This trouble with the Meyers et al. (1992) scheme has long been recognized and alternative parameterizations have been explored (e.g., Liu et al., 2011; Xie et al., 2013; English et al., 2014).

Acknowledgements. We thank the Lawrence Livermore National Laboratory (LLNL) for providing funding through the Multiscale Scientific Discovery through Advanced Computing (SciDAC) project. The research was performed under the auspices of the United States Department of Energy by Lawrence Livermore National Laboratory under contract DE-AC52-07NA27344.

Edited by: R. Neale

\section{References}

Abdul-Razzak, H. and Ghan, S.: A parameterization of aerosol activation: 2. Multiple aerosol types, J. Geophys. Res., 105, 68376844, 2000.

Ackerman, A. S., van Zanten, M. C., Stevens, B., Savic-Jovcic, V., Bretherton, C. S., Chlond, A., Golaz, J.-G., Jiang, H., Khairoutdinov, M., Krueger, S. K., Lewellen, D. C., Lock, A., Moeng, C.-H., Nakamura, K., Petters, M. D., Snider, J. R., Weinbrecht, S., and Zulauf, M.: Large-eddy simulations of a drizzling, stratocumulus-topped marine boundary, Mon. Weather Rev., 137, 1083-1110, doi:10.1175/2008MWR2582.1, 2009.

Bony, S. and Dufresne, J.-L.: Marine boundary layer clouds at the heart of tropical cloud feedback uncertainties in climate models, Geophys. Res. Lett., 32, L20806, doi:10.1029/2005GL023851, 2005. 
Bretherton, C. S. and Park, S.: A New Moist Turbulence Parameterization in the Community Atmosphere Model, J. Climate, 22, 3422-3448, 2009.

Caldwell, P. M., Bretherton, C. S., and Wood, R.: Mixed-Layer Budget Analysis of the Diurnal Cycle of Entrainment in Southeast Pacific Stratocumulus, J. Atmos. Sci., 62, 3775-3791, 2005.

Doran, J. C., Hubbe, J. M., Liljegren, J. C., Shaw, W. J., Collatz, G. J., Cook, D. R., and Hart, R. L.: A technique for determining the spatial and temporal distributions of surface fluxes of heat and moisture over the Southern Great Plains Cloud and Radiation Testbed, J. Geophys. Res., 103, 6109-6121, doi:10.1029/97JD03427, 1998.

English, J. M., Kay, J. E., Gettelman, A., Liu, X., Wang, Y., Zhang, Y., and Chepfer, H.: Contributions of clouds, surface albedos, and mixed-phase ice nucleation schemes to Arctic radiation biases in CAM5, J. Climate, 27, 5174-5197, doi:10.1175/JCLI-D-13$00608.1,2014$.

Forster, P., Ramaswamy, V., Artaxo, P., Berntsen, T., Betts, R., Fahey, D. W., Haywood, J., Lean, J., Lowe, D. C., Myhre, G., Nganga, J., Prinn, R., Raga, G., Schulz, M., and Dorland, R. V.: Changes in atmospheric constituents and in radiative forcing, in: Climate Change 2007: The Physical Science Basis, Contribution of Working Group I to the Fourth Assessment Report of the Intergovernmental Panel on Climate Change, edited by: Solomon, S., Qin, D., Manning, M., Chen, Z., Marquis, M., Averyt, K. B., Tignor, M., and Miller, H. L., Cambridge Univ. Press, UK and New York, 2007.

Frisch, S., Shupe, M., Djalalova, I., Feingold, G., and Poellot, M.: The Retrieval of Stratus Cloud Droplet Effective Radius with Cloud Radars, J. Atmos. Ocean. Tech., 19, 835-842, 2002.

Gettelman, A., Liu, X., Ghan, S. J., Morrison, H., Park, S., Conley, A. J., Klein, S. A., Boyle, J., Mitchell, D. L., and Li, J.-L. F.: Global simulations of ice nucleation and ice supersaturation with an improved cloud scheme in the Community Atmosphere Model, J. Geophys. Res., 115, D18216, doi:10.1029/2009JD013797, 2010.

Gettelman, A., Morrison, H., Santos, S., Bogenschutz, P., and Caldwell, P. M.: Advanced Two-Moment Bulk Microphysics for Global Models. Part II: Global Model Solutions and Aerosol-Cloud Interactions, J. Climate, 28, 1288-1307, doi:10.1175/JCLI-D-14-00103.1, 2015.

Ghan, S. J., Randall, D. A., Xu, K.-M., Cederwall, R., Cripe, D., Hack, J., Iacobellis, S., Klein, S., Krueger, S., Lohmann, U., Pedretti, J., Robock, A., Rotstayn, L., Somerville, R., Stenchikov, G., Sud, Y., Walker, G., Xie, S., Yio, J., and Zhang, M.: A comparison of single column model simulations of summertime midlatitude continental convection, J. Geophys. Res., 105, 20912124, 2000.

Ghan, S. J., Liu, X., Easter, R. C., Zaveri, R., Rasch, P. J., Yoon, J.H., and Eaton, B.: Toward a Minimal Representation of Aerosols in Climate Models: Comparative Decomposition of Aerosol Direct, Semidirect, and Indirect Radiative Forcing, J. Climate, 25, 6461-6476, doi:10.1175/JCLI-D-11-00650.1, 2012.

Hack, J. J. and Pedretti, J. A.: Assessment of Solution Uncertainties in Single-Column Modeling Frameworks, J. Climate, 13, 352-365, doi:10.1175/15200442(2000)013<0352:AOSUIS>2.0.CO;2, 2000.

Hannay, C., Williamson, D. L., Hack, J. J., Kiehl, J. T., Olson, J. G., Klein, S. A., Bretherton, C. S., and Koehler, M.: Evaluation of forecasted Southeast Pacific stratocumulus in the NCAR, GFDL and ECMWF models, J. Climate, 22, 2871-2889, 2009.

Hartmann, D. L., Ockert-Bell, M. E., and Michelsen, M. L.: The Effect of Cloud Type on Earth's Energy Balance: Global Analysis, J. Climate, 5, 1281-1304, 1992.

Haywood, J. M. and Boucher, O.: Estimates of the direct and indirect radiative forcing due to tropospheric aerosols, 2000: A review, Rev. Geophys., 38, 513-543, doi:10.1029/1999RG000078, 2000.

Iacobellis, S. F. and Somerville, R. C. J.: Evaluating parameterizations of the autoconversion process using a singlecolumn model and Atmospheric Radiation Measurement Program measurements, J. Geophys. Res., 111, D02203, doi:10.1029/2005JD006296, 2006.

Klein, S. A., McCoy, R. B., Morrison, H., et al.: Intercomparison of model simulations of mixed-phase clouds observed during the ARM Mixed-Phase Arctic Cloud Experiment. Part I: Single-layer cloud, Q. J. Roy. Meteorol. Soc., 135, 979-1002, doi:10.1002/qj.416, 2009.

Liu, X., Xie, S., Boyle, J., Klein, S. A., Shi, X., Wang, Z., Lin, W., Ghan, S. J., Earle, M., Liu, P. S. K., Wang, Z., and Zelenyuk, A.: Testing cloud microphysics parameterizations in NCAR CAM5 with ISDAC and M-PACE observations, J. Geophys. Res., 116, D00T11, doi:10.1029/2011JD015889, 2011.

Liu, X., Easter, R. C., Ghan, S. J., Zaveri, R., Rasch, P., Shi, X., Lamarque, J.-F., Gettelman, A., Morrison, H., Vitt, F., Conley, A., Park, S., Neale, R., Hannay, C., Ekman, A. M. L., Hess, P., Mahowald, N., Collins, W., Iacono, M. J., Bretherton, C. S., Flanner, M. G., and Mitchell, D.: Toward a minimal representation of aerosols in climate models: description and evaluation in the Community Atmosphere Model CAM5, Geosci. Model Dev., 5, 709-739, doi:10.5194/gmd-5-709-2012, 2012.

Martin, G. M., Johnson, D. W., and Spice, A.: The Measurement and Parameterization of Effective Radius of Droplets in Warm Stratocumulus Clouds, J. Atmos. Sci., 51, 1823-1842, 1994.

Medeiros, B., Stevens, B., Held, I. M., Zhao, M., Williamson, D. L., Olson, J. G., and Bretherton, C. S.: Aquaplanets, Climate Sensitivity, and Low Clouds, J. Climate, 21, 4974-4991, 2008.

Medeiros, B., Williamson, D. L., Hannay, C. E., and Olson, J. G.: Southeast Pacific stratocumulus in the Community Atmosphere Model, J. Climate, 25, 6175-6192, doi:10.1175/JCLI-D11-00503.1, 2012.

Meyers, M. P., DeMott, P. J., and Cotton, W. R.: New primary icenucleation parameterizations in an explicit cloud model, J. Appl. Meteorol., 3, 708-721, 1992.

Mlawer, E. J., Taubman, S. J., Brown, P. D., Iacono, M. J., and Clough, S. A.: Radiative transfer for inhomogeneous atmosphere: RRTM, a validated correlated-k model for the longwave, J. Geophys. Res., 102, 16663-16682, 1997.

Moeng, C. H., Cotton, W. R., Bretherton, C. S., Chlond, A., Khairoutdinov, M., Krueger, S., Lewellen, W. S., MacVean, M. K., Pasquier, J. R. M., Rand, H. A., Siebesma, A. P., Sykes, R. I., and Stevens, B.: Simulation of a stratocumulus-topped PBL: Intercomparison among different numerical codes, B. Am. Meteorol. Soc., 77, 261-278, 1996.

Morrison, H., and Gettelman, A.: A new two-moment bulk stratiform cloud microphysics scheme in the Community Atmosphere Model, version 3 (CAM3). Part I: Description and numerical tests, J. Climate, 21, 3642-3659, 2008. 
Neale, R. B., Chen, C.-C., Gettelman, A., Lauritzen, P. H., Park, S., Williamson, D. L., Conley, A. J., Garcia, R., Kinnison, D., Lamarque, J.-F., Marsh, D., Mills, M., Smith, A. K., Tilmes, S., Vitt, F., Morrison, H., Cameron-Smith, P., Collins, W. D., Iacono, M. J., Easter, R. C., Ghan, S. J., Liu, X., Rasch, P. J., and Taylor, M. A.: Description of the NCAR Community Atmosphere Model (CAM 5.0), NCAR Tech. Note NCAR-TN-486+STR, 274 pp., 2012.

Park, S. and Bretherton, C. S.: The University of Washington Shallow Convection and Moist Turbulence Schemes and Their Impact on Climate Simulations with the Community Atmosphere Model, J. Climate, 22, 3449-3469, doi:10.1175/2008JCLI2557.1, 2009.

Park, S., Bretherton, C. S., and Rasch, P. J.: Integrating Cloud Processes in the Community Atmosphere Model, Version 5, J. Climate, 27, 6821-6856, doi:10.1175/JCLI-D-14-00087.1, 2014.

Randall, D., Krueger, S., Bretherton, C., Curry, J., Duynkerke, P. G., Moncrieff, M., Ryan, B., Starr, D., Miller, M., Rossow, W., Tselioudis, G., and Wielicki, B.: Confronting models with data: The GEWEX Cloud Systems Study. B. Am. Meteorol. Soc., 84, 455-469, doi:10.1175/BAMS-84-4-455, 2003.

Rasch, P. J., Mahowald, N. M., and Eaton, B. E.: Representations of transport, convection, and the hydrologic cycle in chemical transport models: Implications for the modeling of short-lived ands soluble species, J. Geophys. Res., 102, 28127-28138, 1997.

Rauber, R. M., Ochs III, H. T., Di Girolamo, L., et al.: Rain in Shallow Cumulus Over the Ocean: The RICO campaign, B. Am. Meteorol. Soc., 88, 1912-1928, 2007.

Richter, J. H. and Rasch, P. J.: Effects of Convective Momentum Transport on the Atmospheric Circulation in the Community Atmosphere Model, Version 3, J. Climate, 21, 1487-1499, 2008.

Schubert, W. H., Wakefield, J. S., Steiner, E. J., and Cox, S. K.: Marine stratocumulus convection. Part I: Governing equations and horizontally homogeneous solutions, J. Atmos. Sci., 36, 12861307, 1979.

Siebesma, A. P., Bretherton, C. S., Brown, A., Chlond, A., Cuxart, J., Duynkerke, P. G., Jiang, H., Khairoutdinov, M., Lewellen, D., Moeng, C.-H., Sanchez, E., Stevens, B., and Stevens, D. E.: A large eddy simulation intercomparison study of shallow cumulus convection, J. Atmos. Sci., 60, 1201-1219, 2003.

Sobel, A. H. and Bretherton, C. S.: Modeling Tropical Precipitation in a Single Column, J. Climate, 13, 4378-4392, 2000.
Stevens, B. and Seifert, A.: Understanding macrophysical outcomes of microphysical choices in simluations of shallow cumulus convection, J. Meteorol. Soc. Jpn., 86, 143-162, 2008.

Stevens, B., Lenschow, D. H., Vali, G., Gerber, H., Bandy, A., Blomquist, B., Brenguier, J.-L., Bretherton, C. S., Burnet, F., Campos, T., Chai, S., Faloona, I., Friesen, D., Haimov, S., Laursen, K., Lilly, D. K., Loehrer, S. M., Malinowski, S. P., Morley, B., Petters, M. D., Rogers, D. C., Russell, L., Savic-Jovcic, V., Snider, J. R., Straub, D., Szumowski, M. J., Takagi, H., Thornton, D. C., Tschudi, M., Twohy, C., Wetzel, M., and van Zanten, M. C.: Dynamics and Chemistry of Marine Stratocumulus DYCOMS-II, 2003, B. Am. Meteorol. Soc., 84, 579-593, 2003.

VanZanten, M. C., Stevens, B., Nuijens, L., Siebesma, A. P., Ackerman, A. S., Burnet, F., Cheng, A., Couvreux, F., Jiang, H., Khairoutdinov, M., Kogan, Y., Lewellen, D. C., Mechem, D., Nakamura, K., Noda, A., Shipway, B. J., Slawinska, J., Wang, S., and Wyszogrodzki, A.: Controls on precipitation and cloudiness in simulations of trade-wind cumulus as observed during RICO, J. Adv. Model. Earth Syst., 3, M06001, doi:10.1029/2011MS000056, 2011.

Wyant, M. C., Bretherton, C. S., Chlond, A., Griffin, B. M., Kitagawa, H., Lappen, C. L., Larson, V. E., Lock, A., Park, S., de Roode, S. R., Zhao, M., and Ackerman, A. S.: A single-column model intercomparison of a heavily drizzling stratocumulus-topped boundary layer, J. Geophys. Res., 112, D24204, doi:10.1029/2007JD008536, 2007.

Xie, S., Liu, X., Zhao, C., and Zhang, Y.: Sensitivity of CAM5 simulated Arctic clouds and radiation to ice nucleation parameterization, J. Climate, 26, 5981-5999, doi:10.1175/JCLI-D-12$00517.1,2013$.

$\mathrm{Xu}$, K.-M. and Randall, D. A.: Explicit Simulation of Midlatitude Cumulus Ensembles: Comparison with ARM Data, J. Atmos. Sci., 57, 2839-2858, doi:10.1175/15200469(2000)057<2839:ESOMCE>2.0.CO;2, 2000.

Zhang, G. J. and McFarlane, N. A.: Sensitivity of climate simulate simulation to the parameterization of cumulus convection in the Canadian Climate center general circulation model, Atmos. Ocean, 33, 407-446, 1995.

Zhang, M. H., Lin, J. L., Cederwall, R. T., Yio, J. J., and Xie, S. C.: Objective analysis of ARM IOP Data: Method and sensitivity, Mon. Weather Rev., 129, 295-311, 2001. 